\title{
Introduction of a bowser for the transportation of fish seed in Sri Lanka: Impacts and economics
}

\author{
Jayantha Chandrasoma $\uparrow$ and K.B. Chandrani Pushpalatha*
}

National Aquaculture Development Authority of Sri Lanka, 41/1, New

Parliament Road, Pelawatta, Battaramulla, Sri Lanka

$\dagger$ Present address: 153, Horana Road, Panadura, Sri Lanka

* Corresponding author (pushpakbc@gmail.com)

\begin{abstract}
Under the Aquatic Resource Development and Quality Improvement Project (ARDQIP) of the Ministry of Fisheries and Aquatic Recourses of Sri Lanka, which was implemented during 2003-2010, a greater emphasis was laid on the development of culture-based fisheries (CBF) and activities aimed at enhancing fish seed production in the country. One of the foremost needs was to improve facilities for transport of fish seed to meet the envisaged increase in fish seed production and related stocking in remote areas.

ARDQIP was instrumental in designing and introduction of a fish seed transport vehicle (bowser), and this mode of fish seed transport has become very popular in the country. At present, over $90 \%$ of fish seed transport is carried out using bowsers. Introduction of this bowser has made fish seed transport process easier, efficient and economical. The use of the bowser has prevented pollution due to non-necessity of using a large quantity of polythene for packing, making this practice environmentally friendly. Availability of fish seed transport bowsers facilitated enhanced stocking of water bodies and facilitated the development of $\mathrm{CBF}$ in Sri Lanka. Design and the features of the fish seed transport bowser are described in this paper together with discussion on its impact, advantages, disadvantages and economics.
\end{abstract}

Keywords: Culture-based fisheries; fingerling production; fingerling transport; inland fisheries; tropical reservoirs

\section{Introduction}

Fish production from inland fisheries and aquaculture sub-sector in Sri Lanka reached 75,750 tonnes in 2014 (NAQDA 2015). Inland fisheries and culture-based fisheries (CBF) in reservoirs contributed for around $90 \%$ of this production. One of the key factors responsible for the significant increase of this fish production from 
Sri Lankan reservoirs is enhanced stocking of these water bodies with suitable species of fingerlings. Under the Aquatic Resource Development and Quality Improvement Project (ARDQIP) of the Ministry of Fisheries and Aquatic Recourses of Sri Lanka, which was implemented during 2003-2010, a greater emphasis was laid for the development CBF, a stock and recapture strategy, with ownership of the fished stock (De Silva et al. 2006; De Silva 2015) both in perennial and seasonal reservoirs. In reality, development of CBF involves implementing a planned and an enhanced stocking strategy.

In parallel with the development of CBF, ARDQIP implemented several related activities such as improving seed production capacity atAquaculture Development Centres of the National Aquaculture Development Authority of Sri Lanka (NAQDA), establishment of community-based fish nurseries and promotion of establishment of nursery ponds, owned and managed by small scale community groups aimingat supplying fish fingerlings required mainly for the development of CBF.

Enhanced fingerling production, however, was needed to be supplemented with improved facilities of transportation of seed. To address this issue, ARDQIP designed a fish seed transport vehicle in consultation with aquaculture experts, engineers and fibre-glass product manufacturers and provided NAQDA with three fish seed transport vehicles in 2008. This mode of fish seed transport became very popular and by now there are 07 fish seed transport bowsers in Sri Lanka owned by NAQDA, provincial councils and district inland fisher societies.

In this paper, the design and the features of the fish seed transport bowser are described and its advantages, disadvantages and economics are discussed.

\section{Fish seed production}

Details of freshwater fin fish fingerlings and freshwater prawn post larvae stocking in Sri Lanka are given in Table 1. Annual fish fingerling stocking, which was around 3.0 million in 2003, increased significantly in subsequent years. Average annual fish fingerlings and freshwater prawn stocking during 2010-2014 period was 40.8 million and 13.6 million, respectively. More than $90 \%$ of fish fingerlings and freshwater prawn larvae were stocked in reservoirs, the main source of freshwater production in Sri Lanka (Pushpalatha and Chandrasoma 2009; Fernando et al. 2015).

Fish seed production and stocking involved transport of fry produced in Aquaculture Development Centres to community based mini-nurseries and small scale private sector nurseries, transport of fish fingerlings from production centres, community based mini nurseries and private sector nurseries mainly to reservoirs and comparatively small numbers to backyard fish ponds. In respect of freshwater prawn post larvae transportation was from hatcheries of NAQDA to reservoirs and backyard ponds. 
Table 1. Details of stocking of fish fingerlings and freshwater prawn postlarvae in Sri Lanka.

\begin{tabular}{lrr}
\hline Year & $\begin{array}{c}\text { Fish fingerlings } \\
\left(\text { Numbers x } 10^{6}\right)\end{array}$ & $\begin{array}{r}\text { Freshwater prawn } \\
\text { postlarvae } \\
\left(\text { Numbers x } 10^{6}\right)\end{array}$ \\
\hline 2003 & 3.00 & - \\
2006 & 12.75 & 0.36 \\
2007 & 12.18 & 0.44 \\
2008 & 17.48 & 4.11 \\
2009 & 27.07 & 8.06 \\
2010 & 34.34 & 11.51 \\
2011 & 44.72 & 11.36 \\
2012 & 36.98 & 14.53 \\
2013 & 48.79 & 20.43 \\
2014 & 38.95 & 9.92 \\
\hline
\end{tabular}

Transport of fish seed packed in polythene bags

Prior to 2008, the only method used in Sri Lanka for the transportation of fish seed was by packing in oxygenated polythene bags. Fish were packed in bags $(1,220 \mathrm{~mm}$ height x $457 \mathrm{~mm}$ width) made out of gauge 40 polythene. Bags were filled with about15 litres of water.Generally around 250 fish fingerlings $(5-7 \mathrm{~cm}$ in length), 1000 fish fry (2-3 cm in length) or 2,000 post larvae of freshwater prawn (day 45) were packed in a bag. The bags were oxygenated and sealed. These bags were transported in crew cabs, open trucks or any other vehicle, often over long distances, and in some instances taking 5 to $6 \mathrm{hrs}$ to reach a destination situated more than $300 \mathrm{~km}$ away.

\section{Fish seed transport vehicle (bowser)}

Live fish seed transport bowser introduced by ARDQIP consisted of a Fibre Reinforced Plastic (FRP) Tank (3.7 m length x $1.8 \mathrm{~m}$ width x $1.9 \mathrm{~m}$ height) mounted on a 3,000 or $4,000 \mathrm{cc}$ truck with a truck deck of $5 \mathrm{~m} \mathrm{x} 1.9 \mathrm{~m}$. The FRP tank consists of six separate compartments each having water storage capacity of around 800-900 litres. All inner surfaces of compartments were smoothened and the edges were rounded off to prevent injury to fish seed and building-up of microorganisms on the inner surface and to facilitate cleaning and easy drainage. Each compartment has two openings, one on the top and the other at the bottom. Opening at the top with a lockable lid is to introduce fish seed into the compartment, while the opening at the bottom is to drain out fish seed and the water from the compartment. Brass Gate Valves of $4.5 \mathrm{~cm}$ with facilities to couple to 4.5 $\mathrm{cm}$ flexible hose is fixed to the opening at the bottom.

Complete aeration system consisting of PVC pipes for the distribution of air to all six compartments with two Diaphragm type high capacity air pumps (80 Watts; air pumping rate not less than $80 \mathrm{l} / \mathrm{min}$ ) are provided to the FRP tank. The 
power to the above is provided by connecting two DC/AC Inverters or Uninterrupted Power Supplies (UPS) (1 KVA) to the vehicle battery. A $37.0 \mathrm{~kg}$ oxygen cylinder is provided to the vehicle as a backup for the aeration system. Water supply system complete with a water pump with coupling arrangements to Power Take-off (PTO) of the vehicle is provided. A small generator has also been installed in the vehicle to provide backup power.

\section{Advantages of fish seed transport bowser}

A comparison of fish fingerling transport in a bowser with that of using oxygenated polythene bags is given in Table 2 .

\section{Quantity of fish seed}

Approximately 90,000 - 110,000 fish fingerlings or around 300,000 fish fry can be transported in a bowser at a time, whereas in a truck of similar capacity only around 31,000 fish fingerlings (125 bags, each bag with 250 fish fingerlings) or 125,000 fish fry (125 bags, each bag with 1000 fish fry) can be transported. Similarly around 600,000 freshwater prawn post larvae (PL) can be accommodated in a bowser at a time as against 250,000 PL (125 bags, each bag with 2,000 PL) transported in a truck of similar capacity.

\section{Packing and handling}

Time taken for packing of fish and extent of handling of fish during packing areminimal for transport in thebrowser, when compared to packing in oxygenated polythene bags. It was observed that fish fingerlings and fry transported in thebowser are generally very active and less stressed upon reaching the destination, when compared to thosetransported in oxygenated polythene bags. In general, mortalities observed even after long distance transport of fish in thebowser was low (10-15 fish fingerlings). In contrast, mortalities observed after long distance transport of fingerlings in bags was fairly high (5-10 fish fingerlings per bag), sometimes reaching about 5\%. Active, less-stressed fish fingerlings have better chance for survival upon released into reservoirs.

\section{Non-usage of polythene}

Table 2 shows that for the transportation of 90,000 fish fingerlings in oxygenated bags, around $80 \mathrm{~kg}$ of polythene is required. During 2010-2014 period, average annual fish fingerling and freshwater prawn PL stocking in Sri Lanka were 40.8 million and 13.5 million, respectively. If all the fish fingerlings and freshwater prawn post larvae were to be packed in polythene bags for transportation, annually around $36,260 \mathrm{~kg}$ of polythene would be required. Around $90 \%$ of the stocked fish fingerlings and PL of freshwater prawn have been transported in bowsers and this prevented accumulation of around 34.0 tonnes of non-degradable polythene annually in the environment, making this practice an environmentally friendly. In 
these calculations, the amount of polythene saved through transport of fish fry by bowsers were not considered. As the government has given priority to enhance fish seed production and stocking, saving on the polythene will increase further.

Table 2. Fish fingerling transport in a bowser verses oxygenated polythene bags.

Scenarios: Transport distance - 180 km; Number of fish fingerlings - 90,000; Truck for transportation of fish seed packed in bags has the same engine capacity and deck area as the bowser.

\begin{tabular}{|c|c|c|}
\hline Details & Bowser & Oxygenated polythene bags \\
\hline Number of trips & One trip & Three trips ${ }^{1}$ \\
\hline Time taken for packing & Less than 30 minutes & Around 5 hours \\
\hline Labour & 3 person-hours $^{2}$ & 48 person-hours $^{3}$ \\
\hline Use of polythene & Nil & $\approx 80 \mathrm{~kg}^{4}$ \\
\hline Use of oxygen & Nil & $\approx 27 \mathrm{~kg}^{5}$ \\
\hline $\begin{array}{l}\text { Fish handling during } \\
\text { packing }\end{array}$ & Minimal & High \\
\hline $\begin{array}{l}\text { Mortality upon reaching } \\
\text { the destination }\end{array}$ & Very few & Up to $5 \%$ \\
\hline $\begin{array}{l}\text { Costs involved in } \\
\text { transport of fish } \\
\text { fingerlings (SL Rs.) }\end{array}$ & & \\
\hline $\begin{array}{l}\text { Labour costfor } \\
\text { packing }\end{array}$ & 450 & 7,200 \\
\hline $\begin{array}{l}\text { Cost of polythene } \\
\text { used (SL Rs } 268.00\end{array}$ & & \\
\hline per kg) & NA & 21,400 \\
\hline $\begin{array}{l}\text { Cost of oxygen used } \\
\text { (SL Rs. } 300 \text { per }\end{array}$ & & \\
\hline 4.5kg cylinder) & NA & 1,800 \\
\hline $\begin{array}{l}\text { Cost of fuel for the } \\
\text { vehicle }\end{array}$ & 4,885 & 14,655 \\
\hline $\begin{array}{l}\text { Over time \& } \\
\text { subsistence payments }\end{array}$ & 2,000 & 6,000 \\
\hline Total cost & 7,335 & 51,095 \\
\hline
\end{tabular}

\footnotetext{
${ }^{1}$ Bowser can accommodate 90,000 fish fingerlings at a time. In order to transport 90,000 fish fingerlings in polythene bags, truck with a deck area similar to the bowser has to make 3 trips (each trip - max.125 bags, each bag containing 250 fish fingerlings)

${ }^{2} 6$ workers x 30 minutes

${ }^{3} 8$ workers $\mathrm{x} 5 \mathrm{hrs}$ for packing and one worker $\mathrm{x} 8 \mathrm{hrs}$ for preparation of bags.

${ }^{4} 250$ fish fingerlings $\mathrm{x} 360 \mathrm{bags} ; 1 \mathrm{~kg}$ polythene $=4.5 \mathrm{bags}$

$54.5 \mathrm{~kg}$ oxygen cylinder is adequate to fill $60 \mathrm{bags}$

${ }^{6}$ US \$ 1 = SL Rs. 144.00

${ }^{7}$ Fuel consumption rate $-7 \mathrm{~km}$ per litre (cost SL Rs. 95.00 per litre)
} 


\section{Economics}

Transport of fish seed in a bowser is less costly than using oxygenated polythene bags (Table 2). Cost of transportation of fish fingerlings in oxygenated polythene bags is almost 7 times higher. Costs considered are labour involved in packing, polythene and oxygen used, fuel used for the vehicle and overtime and subsistence payments made to the driver and the assistant. A considerable saving has been made through the usage of bowsers for fish seed transport. Savings from non-utilization of polythene alone is around SL Rs.9.2 million per annum (In January 2016, US \$ $1=$ SL Rs.144). Additional capital cost involved in the installation of the FRP tank and related equipment to the truck is around SL Rs. 1.5 million. Depreciated value of this additional capital cost per annum was SL Rs. 0.3 million (depreciation period 5 years). Related depreciated value for all 7 bowsers in operation is around $22 \%$ of the annual saving from the non-usage of polythene.

\section{Disadvantages of the bowser}

There are few reservoirs, which are not accessible by a vehicle. In such situations, it is convenient for people to carry fish seed packed in bags from the closest point a vehicle can reach. Also in cases, where fish seed requirement is comparatively small (e.g. ponds, some seasonal reservoirs), it is more practical and economical to transport fish seed packed in polythene bags.

\section{Conclusion}

Introduction of the fish seed transport bowser has made fish seed transport process convenient, more efficient and economical. Less handling of fish seed during packing and provision of aeration during full duration of transport has resulted in low mortalities and reduced stress. This ensured higher survival of the fish seed upon release to water bodies. It was made possible to cope up with the transport needs related to enhanced fish fingerling stocking during the last few years, mainly due to utilization of the fish seed transport bowsers. It is very important to note that the use of bowsers has prevented pollution of the environment with a large quantity of polythene, making this practice a very environment friendly.

\section{Acknowledgement}

Valuable technical inputs provided by Mr. W.M.S.C.Weerakkody, Engineer, who was attached to ARDQIP during the design and manufacture is greatly appreciated. 


\section{References}

De Silva S.S. 2015. Culture-based fisheries: Why, what, where, how and for whom? 17-25 pp. In: De Silva, S.S., B.A. Ingram, S. Wilkinson (eds), Perspectives on culture-based fisheries developments in Asia. Network of Aquaculture Centres in Asia-Pacific, Bangkok.

De Silva S.S., U.S. Amarasinghe\&T.T.T. Nguyen (eds) 2006. Better- practice approaches for culture-based fisheries development in Asia. ACIAR Monograph No. 120, Australian Centre for International Agricultural Research, Canberra. 96p.

Fernando, W.A.J.R., J. Chandrasoma, K.B.C. Pushpalatha, \& M. Kulathilake 2015. Co-management of the fishery of Senanayake Samudra, a large perennial reservoir in Sri Lanka. Sri Lanka Journal of Aquatic Sciences20 (2): 9-18.

NAQDA 2015. Data \& statistics. Available at www.naqda.gov.lk /data statistics.

Pushpalatha, K.B.C. \& J. Chandrasoma 2009. Culture-based fisheries in minor perennial reservoirs in Sri Lanka: variability in production, stocked species and yield implication. Journal of Applied Ichthyology26: 98-103. 